\title{
Kinetics of Oxidation of Propranolol by Sodium - N - Chloro - p- Toluene Sulphonamide in NaOH medium. A Mechanistic Study
}

\author{
R. Ramachandrappa ${ }^{\mathrm{a}}$, Diwya ${ }^{\mathrm{b}}$, Pushpa Iyengar ${ }^{\mathrm{c}}$ \\ a-Department of Chemistry, Jyoti Nivas College(Autonomous), Koramangala, Bangalore - 560095, Karnataka, India. \\ $b$ - East Point College of Engineering and Technology, Bidarahalli, Virgo Nagar Post Bangalore-560049, Karnataka, India \\ $c^{*}$-East Point College of Engineering and Technology, Bidarahalli, Virgo Nagar Post Bangalore-560049, Karnataka, India.
}

\begin{abstract}
:
Propranolol is used for treating high blood pressure, heart pain, abnormal rhythms of the heart and some neurologic conditions. Kinetics and oxidation of Propranolol (PPL) ((RS)-1-(1-methylethylamino)-3-(1-naphthyloxy)propan-2-ol) by sodium - $\mathrm{N}$ - chloro - p-toluenesulphonamide (Chloramine - T or CAT) in $\mathrm{NaOH}$ medium at $298 \mathrm{~K}$ have been studied. The rate was first order in $[\mathrm{CAT}]_{\mathrm{o}}$, fractional order in $[\mathrm{PPL}]$ and zero order in $\left[\mathrm{OH}^{-}\right]$. Addition of p-toluenesulphonamide, $\mathrm{NaCl}$ and $\mathrm{NaBr}$ did not affect the rate of the reaction. Variation in ionic strength did not affect the rate of the reaction indicating that non - ionic species are involved in the rate limiting step. Dielectric effect of the medium showed positive effect. Rate increased with increase in temperature from $288 \mathrm{~K}$ to $318 \mathrm{~K}$. From the linear Arrhenius plot, activation parameters were computed. Addition of reaction mixture to aqueous acrylonitrile solution did not initiate polymerization, showing the absence of free radicals species. Oxidation products were identified. TsNCINa, the reactive species oxidizes the substrate. Based on kinetic results, reaction stoichiometry and oxidation products, a suitable mechanism have been proposed.
\end{abstract}

Keywords: Alkaline medium, Chloramine - T, Kinetics, Mechanism, Oxidation, Propranolol.

\section{INTRODUCTION:}

Propranolol is a sympatholytic non-selective beta blocker. Sympatholytics are used to treat hypertension, anxiety and panic[1,2]. It was the first successful beta blocker developed. It is used for treating high blood pressure, heart pain (angina), abnormal rhythms of the heart and some neurologic conditions. It also reduces the force of contraction of heart muscle and thereby lowers blood pressure.

Redox reactions have been the subject of detailed mechanistic and kinetic studies as they are most commonly encountered in chemical analysis. Investigation reveals that oxidation of compounds using other oxidants have been carried out[3-10]. Organic haloamines resemble hypohalites in their oxidative behaviour, but are more stable than hypohalites and are developing rapidly as oxidants, disinfectants and antiseptics. Diverse nature of chemistry of haloamines is the consequence of their ability to act as oxidizing and halogenating agents in acidic and alkaline media. They react surprisingly with a wide range of industrially and biologically important functional groups affecting an array of molecular transformations. Haloamines furnish halonium cations in the +1 oxidation state and are generally known to undergo a two electron change in its reaction.

Chloramine- $\mathrm{T}$ (sodium-N-chloro-p-toluenesulfonamide or CAT;p- $\mathrm{CH}_{3} \mathrm{C}_{6} \mathrm{H}_{4} \mathrm{ClSO}_{2} \cdot \mathrm{Na}$ ) a prominent member of the series of haloamines. Literature survey shows that lot of work have been carried out using CAT as oxidant [11-16].

Literature survey revealed no information in the kinetics of oxidation mechanism of Propranolol by any other oxidants. Since the reaction was very fast with Bromamine $-\mathrm{T}$, we have studied the kinetics of oxidation of PPL $((R S)-1-(1-$ methylethylamino)-3-(1-naphthyloxy)propan-2-ol) with $\mathrm{CAT}$ in $\mathrm{NaOH}$ medium at $298 \mathrm{~K}$.

\section{MATERIALS AND METHODS:}

Propranolol (Biocon, Bangalore, India) and Chloramine - T (E.Merck) was used without further purification. An aqueous solution of CAT was standardized iodometrically and preserved in brown bottles to prevent photochemical degradation. All other chemicals used were of analytical grade. Double distilled water was used in preparing all aqueous solutions. Permittivity(Dielectric constant D) of the reaction medium was altered by addition of methanol in varying proportions (v/v) and values of permittivity of methanol - water mixtures reported in literature were employed[17].

2.1 Kinetic procedure

All reactions were performed under pseudo-first order conditions $\left([\mathrm{PPL}]_{0} \gg[\mathrm{CAT}]_{0}\right)$ at $298 \mathrm{~K}$, in a glass stoppered borosil boiling tubes coated black on outside to prevent photochemical effects. For each run, requisite amounts of solution of PPL, $\mathrm{NaOH}$ and $\mathrm{H}_{2} \mathrm{O}$ (total volume kept constant) were introduced into the tube and thermally equilibrated at $298 \pm 1 \mathrm{~K}$. Reaction was initiated by rapid addition of measured amount of CAT solution to the above mixture and was shaken intermittently. Progress of the reaction was monitored by iodometric determination of unreacted CAT in a measured $\left(5 \mathrm{~cm}^{3}\right)$ aliquot of the reaction mixture at different time intervals. Reaction was studied for more than two half-lives. Pseudo-first order rate constants $\left(\mathrm{k}^{\prime}\right)$, calculated from the linear plots of $\log [\mathrm{CAT}]$ versus time were reproducible to $\pm 4 \%$. 


\subsection{Stoichiometry}

Reaction mixtures containing a known excess of [CAT] over [PPL] were kept in presence of $\mathrm{NaOH}$ at $298 \mathrm{~K}$ for 72 hours. Estimation of unreacted CAT showed showed 1:2 stoichiometry to give corresponding product.

$\mathrm{C}_{16} \mathrm{H}_{21} \mathrm{NO}_{2} \mathrm{HCl}+2 \mathrm{TsNClNa}+2 \mathrm{OH}^{-} \longrightarrow \mathrm{C}_{13} \mathrm{H}_{10} \mathrm{O}_{3}+\mathrm{C}_{3} \mathrm{H}_{9} \mathrm{~N} \cdot \mathrm{HCl}+2 \mathrm{TsNNa}+2 \mathrm{H}_{2} \mathrm{O}$

2.3 Product analysis

Reduction product of the oxidant, p-toluenesulphonamide was detected by thin layer chromatography using light petroleum-chloroform-butan-1-ol $(2: 2: 1 \mathrm{v} / \mathrm{v} / \mathrm{v})$ as solvent and iodine as reducing agent $\left(\mathrm{R}_{\mathrm{f}}=.0 .88\right)$. The reported $\mathrm{R}_{\mathrm{f}}$ value is consistent with that given in the literature[18]. Further it was confirmed by its melting point $150-151^{\circ} \mathrm{C}$ (melting point: 149 $151^{\circ} \mathrm{C}$ ) and IR spectra. Oxidation product 3-(naphthalene-1-yloxy)-2-oxopropanal and Isopropylamine was detected by spot tests[19] ie. 2, 4- dinitrophenyl hydrazine test and sodium nitroprusside test and was confirmed by IR spectroscopy. Strong peak for $-\mathrm{CO}$ and $-\mathrm{CHO}$ group was observed around $1725 \mathrm{~cm}^{-1}$ and $\mathrm{NH}$ stretch around $3400 \mathrm{~cm}^{-1}$.

\section{RESULTS}

3.1 Effect of Reactants on the reaction rate

With substrate in excess, at constant $[\mathrm{PPL}],\left[\mathrm{OH}^{-}\right]$and temperature, plots of log $[\mathrm{CAT}]$ vs time were linear indicating a first order dependence of rate on $[\mathrm{CAT}]_{\mathrm{o}}$. The rate constant $\mathrm{k}^{\prime}$ was not affected by a change in $[\mathrm{CAT}]_{\mathrm{o}}$ (Table 1$)$ confirming first order dependence on $[\mathrm{CAT}]_{\mathrm{o}}$. Under identical experimental conditions, an increase in [PPL] lead to increase in $\mathrm{k}^{\prime}$ (Table1) and a plot of $\log \mathrm{k}^{\prime}$ vs $\log$ [PPL] was linear (Fig. 1) with a positive slope of 0.76 indicating a fractional order dependence on [PPL]. The rate of the reaction was unaffected with increase in $[\mathrm{NaOH}](\mathrm{Table} 1)$. Plot of log $\mathrm{k}^{\prime}$ vs $\log$ $[\mathrm{NaOH}]$ showed a zero order dependence on $\left[\mathrm{OH}^{-}\right]$.

Table 1: Effect of $[\mathrm{CAT}],[\mathrm{PPL}]$ and $[\mathrm{NaOH}]$ on the reaction rate

\begin{tabular}{llll}
\hline $10^{4}[\mathrm{CAT}]_{\mathrm{o}}$ & $10^{3}[\mathrm{PPL}]$ & $10^{5}[\mathrm{NaOH}]$ & $10^{3} \mathrm{k}^{\prime}$ \\
\hline $\mathrm{mol} \mathrm{dm}^{-3}$ & $\mathrm{~mol} \mathrm{dm}^{-3}$ & $\mathrm{~mol} \mathrm{dm}^{-3}$ & $\mathrm{~s}^{-1}$ \\
\hline 6.0 & 10.0 & 20.0 & 1.112 \\
10.0 & 10.0 & 20.0 & 1.247 \\
20.0 & 10.0 & 20.0 & 1.110 \\
10.0 & 5.0 & 20.0 & 0.710 \\
10.0 & 10.0 & 20.0 & 1.247 \\
10.0 & 15.0 & 20.0 & 1.900 \\
10.0 & 20.0 & 20.0 & 2.110 \\
10.0 & 10.0 & 1.0 & 1.150 \\
10.0 & 10.0 & 4.0 & 1.247 \\
10.0 & 10.0 & 10.0 & 1.287 \\
10.0 & 10.0 & 200.0 & 1.337 \\
& & & \\
\hline
\end{tabular}

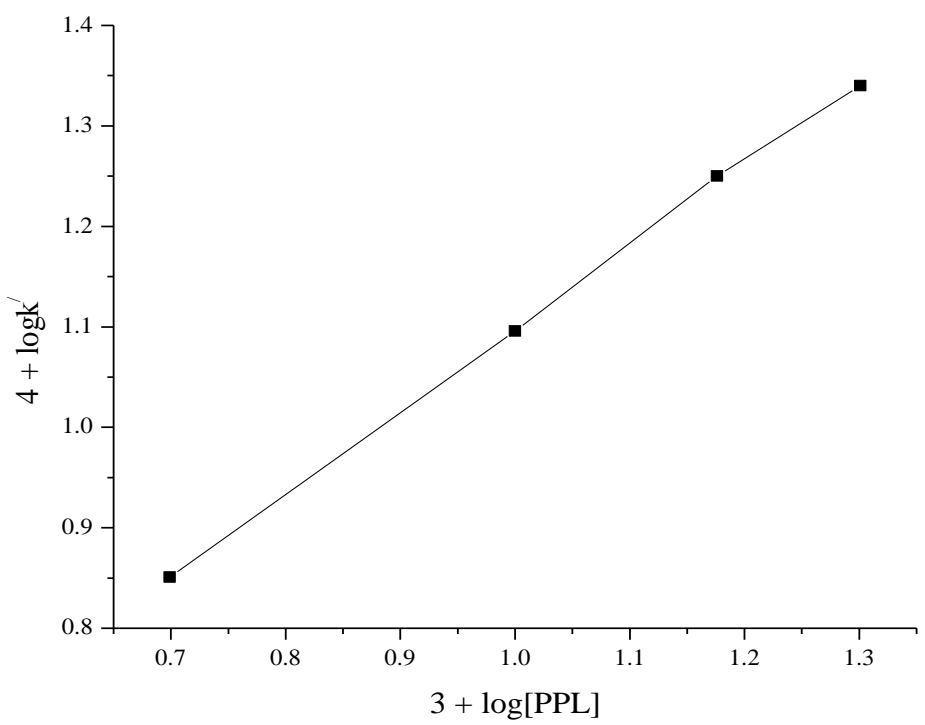

Fig 1: Effect of $[\mathrm{PPL}]$ on the reaction rate 
IOSR Journal of Pharmacy

Vol. 2, Issue 3, May-June, 2012, pp.493-499

3.2 Effect of halide ions and p-toluenesulphonamide(PTS)

At constant $\left[\mathrm{OH}^{-}\right]$, addition of $\mathrm{NaCl}$ or $\mathrm{NaBr}$ did not affect the reaction rate (Table 2). It reflected that the rate of the reaction depends only on $\left[\mathrm{OH}^{-}\right]$.

Addition of the reduction product of the oxidant, PTS did not affect the rate (Table 2) which indicates its non involvement in pre equilibrium step with the oxidant.

Table 2: Effect of Halide Ions, $\mathrm{PTS}, \mathrm{NaClO}_{4}$ on the reaction rate

\begin{tabular}{lllll}
\hline $10^{4}[$ conc $]$ & $\mathrm{PTS}$ & $\mathrm{NaCl}$ & $\mathrm{NaClO}_{4}$ & $\mathrm{NaBr}$ \\
\hline $\mathrm{mol} \mathrm{dm}^{3}$ & $10^{3} \mathrm{k}^{\prime}\left(\mathrm{s}^{-1}\right)$ & $10^{3} \mathrm{k}^{\prime}\left(\mathrm{s}^{-1}\right)$ & $10^{3} \mathrm{k}^{\prime}\left(\mathrm{s}^{-1}\right)$ & $10^{3} \mathrm{k}^{\prime}\left(\mathrm{s}^{-1}\right)$ \\
\hline 0.0 & 1.247 & 1.247 & 1.247 & 1.247 \\
10.0 & 1.730 & 1.140 & 1.310 & 1.102 \\
50.0 & 1.350 & 1.025 & 1.012 & 1.234 \\
100.0 & 1.210 & 1.230 & 1.210 & 1.200 \\
\hline
\end{tabular}

\subsection{Effect of ionic strength and dielectric constant}

Variation in ionic strength using $\mathrm{NaClO}_{4}$ solution did not affect the rate of the reaction (Table 2) indicating that nonionic species are involved in the rate limiting step.

The effect of varying solvent composition and dielectric constant on the rate has been described in several studies. Dielectric constant (D) of the medium was varied by adding methanol to the reaction mixture. Addition of methanol resulted in increase in the rate of the reaction. Plot of $\left(10^{2} / \mathrm{D}\right) \mathrm{vs} \operatorname{logk}($ Table 3$)$ was found to be linear with a positive slope 2.16 (Fig.2). The positive dielectric effect, in present case, supports the involvement of positive ion dipole interaction in the ratelimiting step. Blank experiments showed that $\mathrm{MeOH}$ was oxidized slowly $(\sim 3 \%)$ by the oxidants under the experimental conditions. This was corrected for the calculations in the net reaction for the rate constant.

Table 3: Effect of Dielectric Constant on the reaction rate

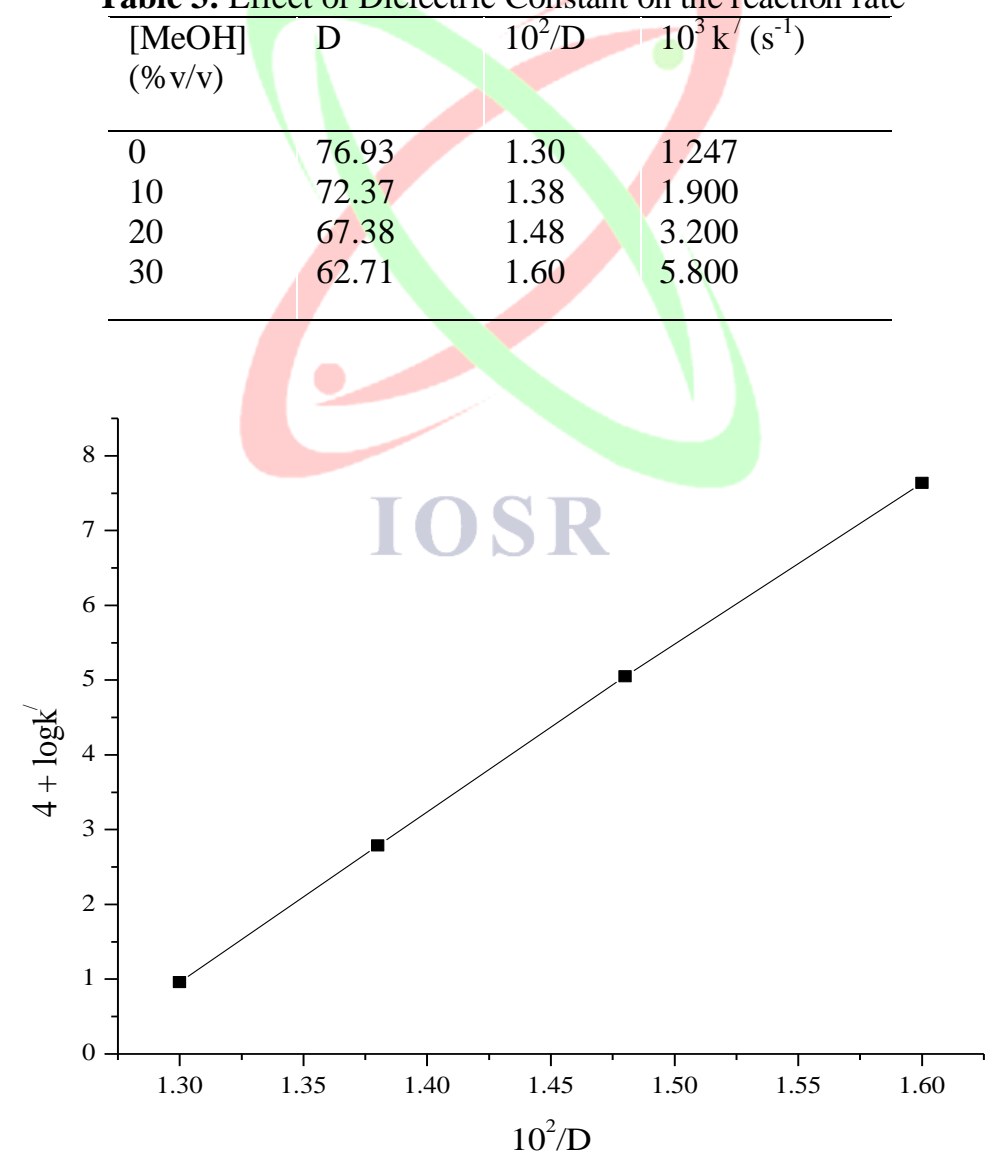

Fig. 2: Effect of Dielectric constant of the medium on the reaction rate 


\subsection{Effect of temperature on the reaction rate}

Reaction was studied over a range of temperature $288 \mathrm{~K}$ to $318 \mathrm{~K}$ (Table 4) by varying [PPL] and keeping other experimental conditions constant. It was found that the rate increased with increase in temperature (Fig. 3).

From the linear Arrhenius plot of logk ${ }^{\prime}$ vs 1/T (Fig. 4), activation parameters were computed(Table 5).

Table 4: Effect of [PPL] at different temperatures

\begin{tabular}{llrl}
\hline $10^{3}[\mathrm{PPL}]$ & \multicolumn{3}{c}{$10^{3} \mathrm{k}^{\prime}\left(\mathrm{s}^{-1}\right)$} \\
\cline { 2 - 4 } $\mathrm{mol} \mathrm{dm}^{3}$ & $288 \mathrm{~K}$ & $298 \mathrm{~K}$ & $308 \mathrm{~K}$ \\
\hline 5.0 & 0.371 & 0.710 & 1.122 \\
10.0 & 0.616 & 1.247 & 1.862 \\
15.0 & 0.707 & 1.900 & 2.187 \\
20.0 & 1.174 & 2.110 & 3.715 \\
\hline
\end{tabular}

Table 5: Effect of Temperature on the rate of the reaction

\begin{tabular}{lll}
\hline Temperature $(\mathrm{K})$ & $10^{3} \mathrm{k}^{\prime}\left(\mathrm{s}^{-1}\right)$ & Activation parameters \\
\hline 288 & 0.410 & $\mathrm{Ea}=78.07 \mathrm{~kJ} \mathrm{~mol}^{-1}$ \\
298 & 1.247 & $\Delta \mathrm{H}^{\neq}=75.983 \mathrm{~kJ} \mathrm{~mol}^{-1}$ \\
308 & 3.200 & $\Delta \mathrm{G}^{\neq}=21.472 \mathrm{~kJ} \mathrm{~mol}^{-1}$ \\
318 & 7.900 & $\Delta \mathrm{S}^{\neq}=-179.90 \mathrm{JK}^{-1} \mathrm{~mol}^{-1}$ \\
& & $\log \mathrm{A}=10.786$ \\
\hline
\end{tabular}

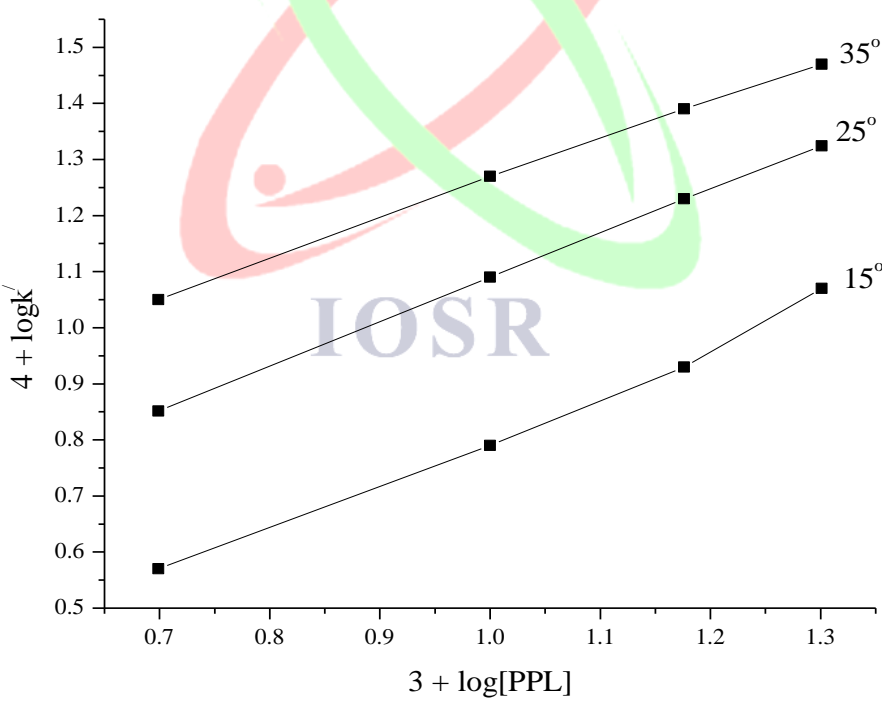

Fig. 3: Effect of [PPL] at different temperatures in acid medium 


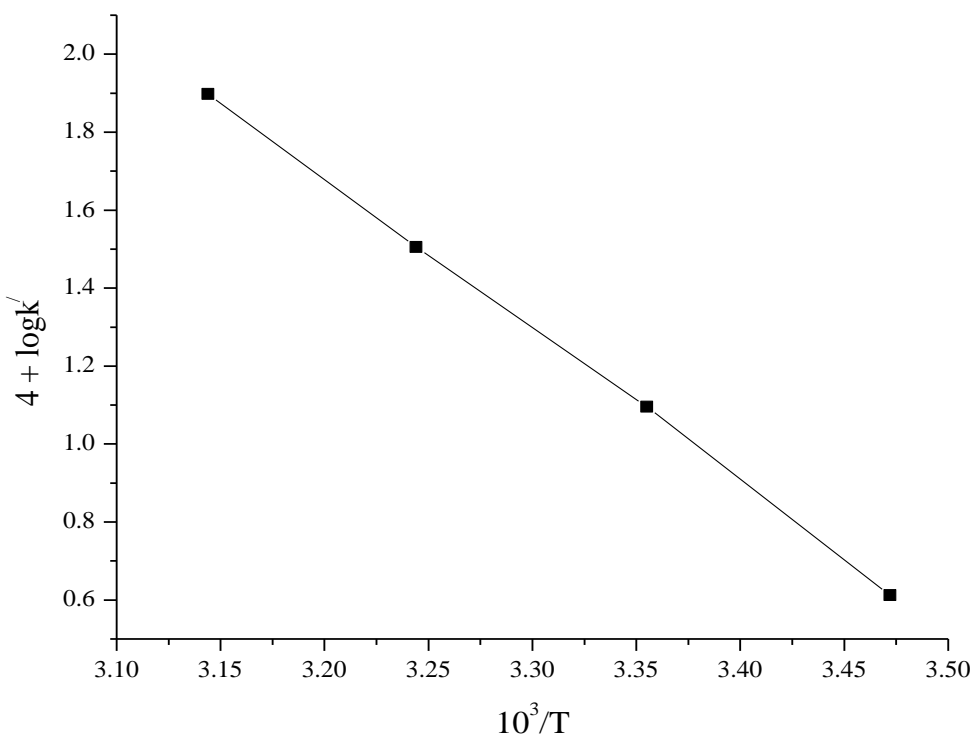

Figure 4: Effect of temperature on the rate of the reaction

3.4 Test for free radicals

Addition of reaction mixture to aqueous acrylonitrile solution did not initiate polymerization, showing the absence of free radicals species.

\section{DISCUSSION}

Investigations by Pryde and Soper[20], Morris et.al[21] and Bishop and Jinnings[22] on sodium-Nhaloarenesulfonamides have shown that Chloramine-T behave as strong electrolyte in aqueous solution forming different species as shown in equations.

TsNCINa

(Here Ts=p- $\mathrm{CH}_{3} \mathrm{C}_{6} \mathrm{H}_{4} \mathrm{SO}_{2}$ )

$\mathrm{TsNCl}^{-}+\mathrm{H}^{+}$

$2 \mathrm{TsNHCl}$

$\mathrm{TsNHCl}+\mathrm{H}_{2} \mathrm{O}$

$\mathrm{TsNCl}_{2}+\mathrm{H}_{2} \mathrm{O}$

$\mathrm{HOCl}$
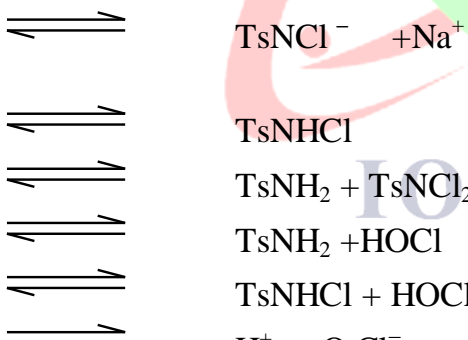

$\mathrm{TsNH}_{2}+\mathrm{TsNCl}_{2}$

$\mathrm{TsNH}_{2}+\mathrm{HOCl}$

$\mathrm{TsNHCl}+\mathrm{HOCl}$

$\mathrm{H}^{+}+\mathrm{O} \mathrm{Cl}^{-}$
(2)

The possible oxidizing species in basic medium are $\mathrm{TsNHCl}, \mathrm{TsNCl}_{2}$ and $\mathrm{HOCl}$. If $\mathrm{TsNCl}_{2}$ were to be the reactive species, the rate law predicts a second order dependence of rate on [CAT] which is contrary to the experimental observations. If $\mathrm{HOCl}$ is primarily involved, a first order retardation of the rate by the added p-toluenesulphonamide is expected. Since no such effect is noticed, $\mathrm{HOCl}$ can be ruled out as the oxidizing species.

Since the rate of the reaction is independent of $[\mathrm{NaOH}], \mathrm{TsNH}_{2} \mathrm{Cl}^{+}$cannot be the oxidizing species. Hence CAT (TsNClNa) itself can oxidize the propranolol under the conditions employed.

Based on the preceding discussion and observed kinetic results, a mechanism (Scheme 1) is proposed for the oxidation of PPL by CAT in basic medium.

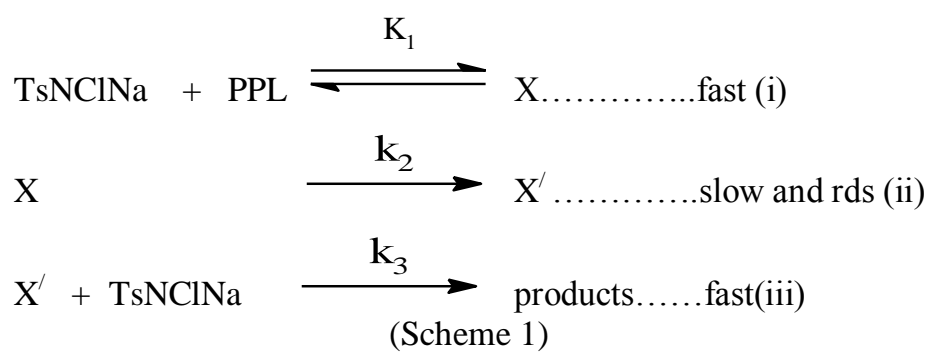


In Scheme 1, $X$ and $X^{\prime}$ represents the intermediate species, whose structures are shown in Scheme 2 in which a detailed mechanistic interpretation of PPL oxidation by CAT in basic medium is proposed. In this, the oxidant species TsNCINa reacts with the substrate in a fast equilibrium step to form complex (X). $\mathrm{X}$ decomposes to intermediate $\mathrm{X}^{\prime}$ in rate limiting step. $\mathrm{X}^{\prime}$ reacts with another mole of TsNCINa to form products. Two moles of the oxidant are consumed to yield the products.

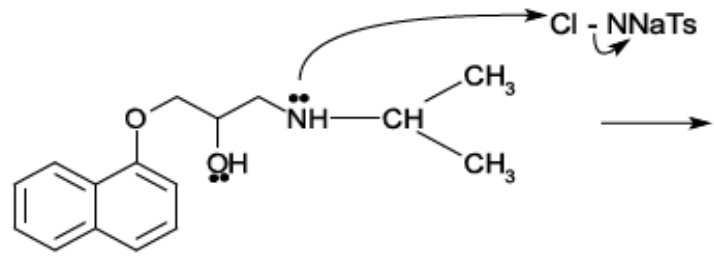<smiles>CC(C)NC1(C)CCCC1C</smiles>
$(X)$

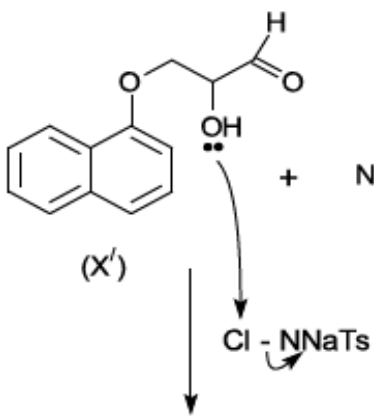<smiles>CC(C)N</smiles><smiles>C=C(C=CCO)OCC(O)C=[NH+]C(C)C</smiles><smiles>O=CC(COc1cccc2ccccc12)[GeH]Cl</smiles><smiles>CCOC(COc1cccc2ccccc12)C(=O)Cl</smiles><smiles>O=CC(=O)COc1cccc2ccccc12</smiles>

Scheme 2

From step (i), (ii) and (iii) of Scheme 1, we have

Rate $=\frac{\mathrm{k}_{1} \mathrm{k}_{2}[\mathrm{CAT}]_{\mathrm{t}}[\mathrm{PPL}]}{\mathrm{k}_{-1}}$

Rate law Equation (8) is in agreement with the experimental results.

Variation in ionic strength of the medium did not alter the rate indicating the involvement of non-ionic species in the rate limiting step. Addition of halide ions had no effect on the rate indicating that no interhalogen or free chlorine is formed. The positive dielectric effect observed in present case supports the positive ion - dipole interactions in the rate limiting step. Proposed mechanism is further supported by the moderate values of energy of activation and other activation parameters. Fairly high positive values of free energy of activation and enthalpy of activation indicate that the transition state is highly solvated, while the large negative entropy of activation suggests the formation of the compact activated complex with less degrees of freedom.

\section{CONCLUSION}

Kinetics and oxidation of Propranolol by sodium-N-chloro-p-toluenesulfonamide (Chloramine-T or CAT) in aqueous $\mathrm{NaOH}$ have been studied at $298 \mathrm{~K}$. Activation parameters were computed. The positive dielectric effect, in the present case, supports the involvement of positive ion dipole interaction in the rate-limiting step. Major oxidation product was identified as 3-(naphthalene-1-yloxy)-2-oxopropanal and Isopropylamine. TsNCINa is the reactive species which reacts with the substrate. Based on kinetic results and reaction stoichiometry, a suitable mechanism has been proposed. 
IOSR Journal of Pharmacy

Vol. 2, Issue 3, May-June, 2012, pp.493-499

\section{REFERENCES}

[1] J. Kornischka, J. Cordes, M.W.Agelink, 40 years beta-adrenoceptor blockers in psychiatry. Fortschritte Der Neurologie-Psychiatrie, 75(4), 2007, 199-210.

[2] V .Vieweg, A .Pandurangi, J .Levenson, J .Silverman, The consulting psychiatrist and the polydipsiahyponatremia syndrome in schizophrenia, International Journal of Psychiatry in Medicine, 24 (4), 1994, 275-303.

[3] Puttaswamy, R. Ramachandrappa and N.M. Made Gowda, Kinetics and Mechanism of Rurhenium(III) catalyzed oxidation of Secondary Alcohols by Bromamine - T in Hydrochloric acid solutions, Synthesis and Reactivity in Inorganic and Metal-Organic Chemistry, 32(7), 2002, 1263.

[4] Puttaswamy and J.P. Shubha, Kinetics and mechanism of sodium N -halo-p-toluenesulfonamides oxidation of diclofenac in alkaline medium, AIChE Journal, 55, 2009, 3234.

[5] Diwya, R. Ramachandrappa and Pushpa Iyengar, Kinetics and Mechanism of oxidation of Miglitol by Bromamine -T (BAT) in $\mathrm{HCl}$ medium using $\mathrm{RuCl}_{3}$ as catalyst, J Chem Pharm Res, 4(3), 2012, 1676.

[6] R. Ramachandrappa, Diwya, PushpaIyengar, Kinetic and mechanistic studies on the oxidation of Voglibose by Bromamine - T in $\mathrm{HCl}$ medium, RJPBCS, 3(1), 2012, 837.

C.G. Nair, R. Lalithakumari and P.I. Senan, Bromamine-T as a new oxidimetric titrant, Talanta, 25, 1978, 525.

[8] Puttaswamy and R.V. Jagadeesh, Mechanistic Studies of Oxidation of Thiols to Disulfides by Sodium NChloro-p-toluenesulfonamide in an Alkaline Medium: A Kinetic Approach, Ind Eng.Chem Res, 45(5), 2006, 1563.

[9] P.R. Rangaraju, T.V. Venkatesha and R. Ramachandrappa, Kinetic and mechanistic studies on the Oxidation of Tinidazole by Bromamine - T in $\mathrm{HCl}$ medium, RJPBCS, 2(4), 2011, 947.

[10] C.H. Vinod Kumar, K.N. Shivananda, R.V. Jagadeesh, C. Naga Raju, Ruthenium complex catalyzed oxidative conversion of aliphatic amines to carboxylic acids using bromamine-T: Kinetic and mechanistic study, J Mol Cat A ,311, 2009, 23.

[11] Usha Joseph, R. Ramachandrappa, Pushpa Iyengar, Kinetics of Oxidation of Pioglitazone by Chloramine - $\mathrm{T}$ in $\mathrm{HCl}$ medium- A mechanistic Approach, International Journal of Universal Pharmacy and Life Sciences, 2(2), 2012, 85.

[12] K.N. Mohana, N. Prasad, Ruthenium(III)- catalyzed oxidation of 2- phenylethylamine with sodium N chlorobenzenesulphonamide in hydrochloric acid solution: A kinetic and mechanistic study, Journal of Molecular Catalysis A, 266(1-2), 2007, 267-273.

[13] Diwya, R Ramachandrappa, Pushpa Iyengar, Oxidation of Metoprolol by Chloramine - T(CAT) in $\mathrm{NaOH}$ medium using $\mathrm{RuCl}_{3}$ : A kinetic study, International Journal of Universal Pharmacy and Life Sciences, 2(3), 2012, 1.

[14] B. Jayaram, S.M. Mayanna, Mechanism of Oxidation of Caffeine by sodium n-chloro benzene sulphonamide: a kinetic study, Tetrahedron, 39(13), 1983, 2271-2275.

[15] Subbaiah Meenakshisundaram, R.M.Sockalingam, Os(VIII)- catalyzed oxidation of sulphides by sodium salt of N- chlorobenzenesulphonalide, J Mol Catal A Chem, 160(2), 2000, 269-275.

[16] Y.I. Hassan, N.H.M. Saeed, Kinetics and Mechanism of Oxidation of Diethyl Ether by Chloramine - T in acidic medium, E-journal of Chemistry, 9(2), 2012, 642-649

[17] G. Akerloff, Dielectric constants of some organic solvent - water mixtures at various temperatures, $J \mathrm{Am}$ chem Soc, 54, 1932, 4125.

[18] A.I.Vogel, Text Book of Practical Organic Chemistry $\left(5^{\text {th }}\right.$ Edition, ELBS, London, 1989).

[19] F.Feigl, Spot tests in organic analysis $\left(5^{\text {th }}\right.$ Edition, Elsevier, Amsterdam, 1966) J.C.Morris, J.A.Salazar, M.A.Wineman, Equilibrium studies on Chloro compounds: The ionization constant of N- Chloro- p- toluenesulphonamide, J Amer Chem Soc, 70, 1948, 2036.

[22] E. Bishop, V.J. Jinnings, Titrimetric Analysis with Chloramine $-\mathrm{T}$ : The status of Chloramine $-\mathrm{T}$ as a Titrimetric Reagent, Talanta, 1, 1958, 197. 